\title{
Effect of colchicine on intestinal function in the rat
}

\author{
R. J. LEVIN \\ From the Department of Physiology, University of Sheffield, Sheffield
}

\begin{abstract}
EDITORIAL SYNOPSIS Colchicine, being a powerful inhibitor of mitosis, might be expected to influence intestinal function in view of the rapid turnover of the cells of the mucosa. It has in fact been found to reduce absorption of certain sugars and also has an effect on motility and food intake in the rat.
\end{abstract}

Studies on the effect of malabsorption on the functions of the small intestine would be greatly facilitated if such states could be routinely induced in the laboratory. A number of efforts to achieve such states in experimental animals have met with little success (Althausen and Grodsky, 1961; Williams and Laster, 1963) but the use of antimitotic drugs, such as aminopterin and colchicine, cause a pathological villous architecture similar to that found in many types of malabsorption (Baserga and Morsiani, 1958; Williams, 1963; Clark and Harland, 1963). Studies on the effect of colchicine on intestinal absorption have, however, only been carried out in conscious animals (Clark and Harland 1963, Luketic and Shapiro, 1964) where absorption depends not only on the activity of the mucosal cells of the intestinal epithelium but also on factors such as gastric emptying, intestinal motility, blood flow, etc. In order to avoid the influence of a number of these factors the effect of colchicine on intestinal function has been investigated using a recently developed technique in the anaesthetized rat in vivo and on sacs of isolated, everted intestine incubated in vitro.

\section{METHODS}

White, male rats (200-220 g.) of the Sheffield strain were injected intraperitoneally with colchicine (British Drug Houses, laboratory reagent) made up freshly each day by dissolving $10 \mathrm{mg}$. in $10 \mathrm{ml}$. of $0.9 \%$ sodium chloride; $0.1 \mathrm{mg} . / 100 \mathrm{~g}$. body weight was injected into each rat each day for three days. Control rats were injected with similar volumes of $0.9 \%$ sodium chloride. During treatment both control and colchicine groups were allowed access to tap water ad lib but no food was given.

\section{ABSORPTION TECHNIQUES}

Absorption in vivo was studied in the anaesthetized rat (Nembutal i.p.) by the method of Sheff and Smyth (1955). A known volume of $0.9 \%$ sodium chloride containing the sugar under investigation was circulated through the intestine cannulated at the level of the ligament of Trietz and the ileocaecal junction. At the end of the 15-minute circulation the apparatus and intestine were washed out with $0.9 \% \mathrm{NaCl}$ into a known volume, and the sugar estimated. The amount absorbed was obtained by subtracting the amount recovered from that originally present. Transfer in vitro was studied by the everted sac technique (Wilson and Wiseman, 1954) as used by Barry, Matthews, and Smyth (1961). The combined jejunum and ileum was removed under nembutal anaesthesia, everted, divided into five equal parts. The middle fifth, usually $16 \mathrm{~cm}$. long, was taken for incubation in $15 \mathrm{ml}$. of Krebs's bicarbonate saline (Krebs and Henseleit, 1932) containing the sugar under investigation. One millilitre of the same solution was placed inside the everted segment. The incubation was carried out at $38^{\circ} \mathrm{C}$. for 30 minutes with the buffer in equilibrium with $95 \% \mathrm{O}_{2}, 5 \% \mathrm{CO}_{2}$. Glucose and other reducing sugars were estimated by the method of Nelson (1944) as modified by Somogyi (1945). Fat-free dry weights of small intestine were obtained by removing the combined jejunum and ileum and drying overnight at $100^{\circ} \mathrm{C}$. The tissue was then extracted with ether, redried, and weighed.

\section{MALTASE ACTIVITY}

This was estimated by homogenizing the blotted and weighed combined jejunum and ileum (removed from nembutal-anaesthetized rats) in $100 \mathrm{ml}$. Krebs's bicarbonate saline. A $10 \mathrm{ml}$. aliquot of this homogenate was then added to $15 \mathrm{ml}$. of the Krebs's buffer containing $250 \mathrm{mg}$. of maltose. This final digest mixture was gassed in a $150 \mathrm{ml}$. incubation flask for three minutes with $95 \%$ $\mathrm{O}_{2}, 5 \% \mathrm{CO}_{2}$ and incubated for 30 minutes at $38^{\circ} \mathrm{C}$. The amount of glucose formed was estimated by the method of Huggett and Nixon (1957) as modified by Dahlqvist (1961). The enzyme activity was expressed on a whole intestine (absolute) basis and on a grams wet weight basis (Levin, Newey, and Smyth 1965).

\section{HISTOLOGY}

Small intestine was fixed in vivo in anaesthetized rats by opening the bowel along the antimesenteric line and pouring Bouins fixative over the mucosa. The fixed portion was removed, gently flattened mucosa upwards 
on a piece of card and floated in Bouins solution. The tissue was dehydrated and mounted in paraffin wax. Routine sections were cut at $7 \mu$ and stained with haematoxylin and eosin.

\section{ALIMENTARY TRACT MOTILITY}

Conscious rats were fed $4 \mathrm{ml}$. of a dilute barium sulphate suspension (Micropaq, diluted with an equal volume of $0.9 \% \mathrm{NaC} 1$ ) by stomach tube. After 30 minutes each rat was killed by a blow on the head and the abdomen rapidly opened. Ligatures were quickly tied at the pylorus and at the head of the barium column which could easily be seen through the thin wall of the intestine. The technique is simple and allows a rapid determination of alimentary transit time.

\section{RESULTS}

EFFECTS ON INTESTINAL DRY WEIGHT AND MORPHOLOGY The effect of colchicine injections on the dry weight of the small intestine of three groups of control and injected rats over the threeday treatment period is shown in Table I. On day 1

\section{TABLE I}

DRY WEIGHTS OF THE SMALL INTESTINE (COMBINED JEJUNUM AND ILEUM) OF VARIOUS GROUPS OF CONTROL AND COLCHICINETREATED RATS ${ }^{1}$

\begin{tabular}{|c|c|c|c|c|}
\hline \multirow[b]{2}{*}{ Day } & \multicolumn{2}{|c|}{ Intestinal Dry Weight $(\mathrm{g})}$. & \multirow{2}{*}{$\begin{array}{l}\text {-Percentage } \\
\text { Change }\end{array}$} & \multirow{2}{*}{$\begin{array}{l}\text { Significance } \\
\text { of Diffe- } \\
\text { rence bet- } \\
\text { ween Means }\end{array}$} \\
\hline & Controls & $\begin{array}{l}\text { Colchicine } \\
\text { Treated }\end{array}$ & & \\
\hline $\begin{array}{l}1 \\
2 \\
3\end{array}$ & $\begin{array}{l}0.92 \pm 0.02(7) \\
0.81 \pm 0.02(8) \\
0.74 \pm 0.03(15)\end{array}$ & $\begin{array}{l}0.86 \pm 0.04(7) \\
0.64 \pm 0.02(8) \\
0.60 \pm 0.02(17)\end{array}$ & $\begin{array}{l}-6.5 \\
-21.0 \\
-18.9\end{array}$ & $\begin{array}{l}\mathrm{p}>0.7 \\
\mathrm{p}<0.001 \\
\mathrm{p}<0.001\end{array}$ \\
\hline
\end{tabular}

${ }^{1}$ Results are expressed as the mean \pm S.E. Figures in brackets represent the number of animals.

there was no significant change in the dry weight but by day 2 a highly significant decrease $(21 \%)$ in intestinal solids was observed when compared with intestines from control animals. A $19 \%$ reduction in dry weight occurred by day 3 ( $p<0.001$ ). Histological sections from a number of rats injected with colchicine showed marked changes in the lamina propia (invasion by leucocytes) and an increase in the number of crypt cells arrested in mitosis but the villi did not appear grossly abnormal (Figures 1,2 ). A few of the intestines from the treated rats had areas of villous atrophy similar in appearance to that noted by Williams (1963) and Clark and Harland (1963) but such areas were spotty and were surrounded by a normal villous pattern (Figure 3 ). This wide variation in the histological picture was mirrored in the large scatter found in the functional studies of intestine from colchicine-treated rats.

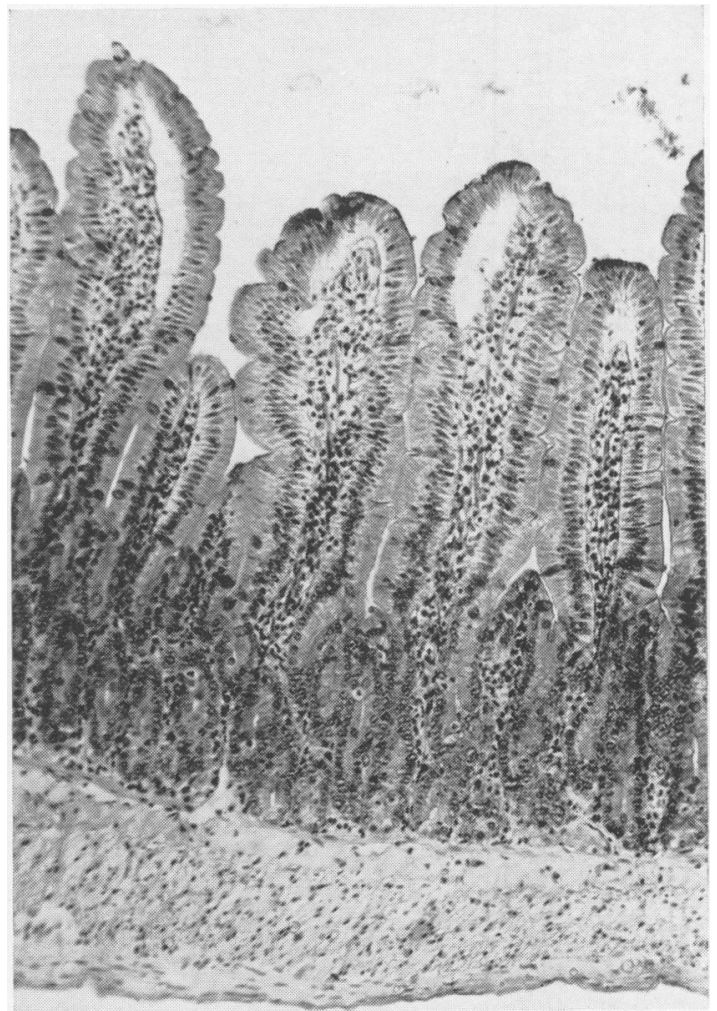

FIG. 1. Section of duodenal mucosa from control rat killed on day 3. Haematoxylin and eosin, approximately $\times 125$.

Although, because of technical difficulties, it is not yet possible to apportion the loss of weight in the small intestine to specific changes either in intracellular material or to a decreased number of cells in the mucosa, it is obvious that the loss must be taken into account when digestive and absorptive functions of the small bowel are assessed. Levin et al. (1965) have previously drawn attention to possible effects that changes in weight of the gut may have on intestinal function.

EFFECTS ON ABSORPTION IN VIVO In Table II the results for the absorption of a number of sugars in control and colchicine-treated rats are collected. Colchicine injections greatly affected glucose absorption so that by day 3 the absorption compared to the controls was depressed by $59 \%$, a highly significant result $(p<0 \cdot 001)$. Colchicine treatment had a similar marked effect on the absorption of galactose although the depression was not as profound; by day 3 galactose absorption was depressed by $38 \%$ (significant at $\mathrm{p}<0.05$ ). Fructose absorption, tested on day 3 only, was depressed $30 \%$ and this 


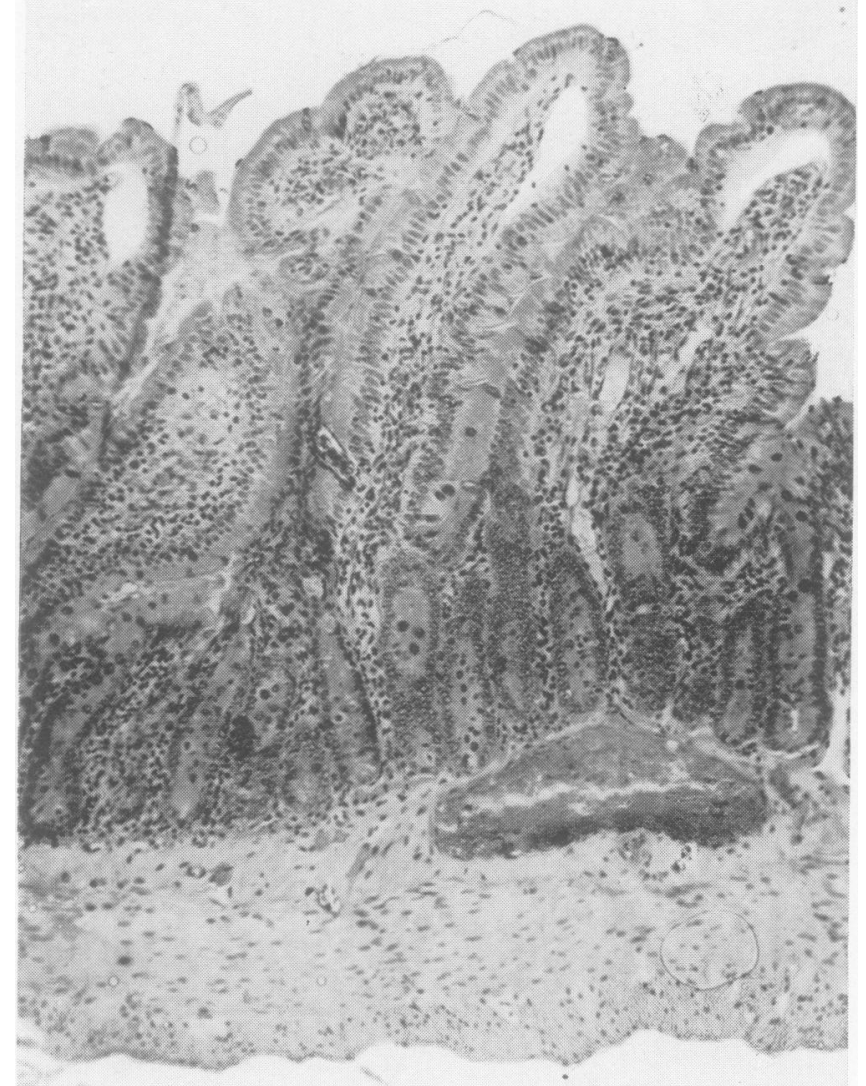

FIG. 2. Section of duodenum from rat injected with colchicine for three days $(0.1 \mathrm{mg} .100 \mathrm{~g}$. body weight). Haematoxylin and eosin, approximately $\times 125$. Other than the infiltration of the lamina propria by leucocytes and enlarged blood vessels the mucosa has a relatively normal appearance.

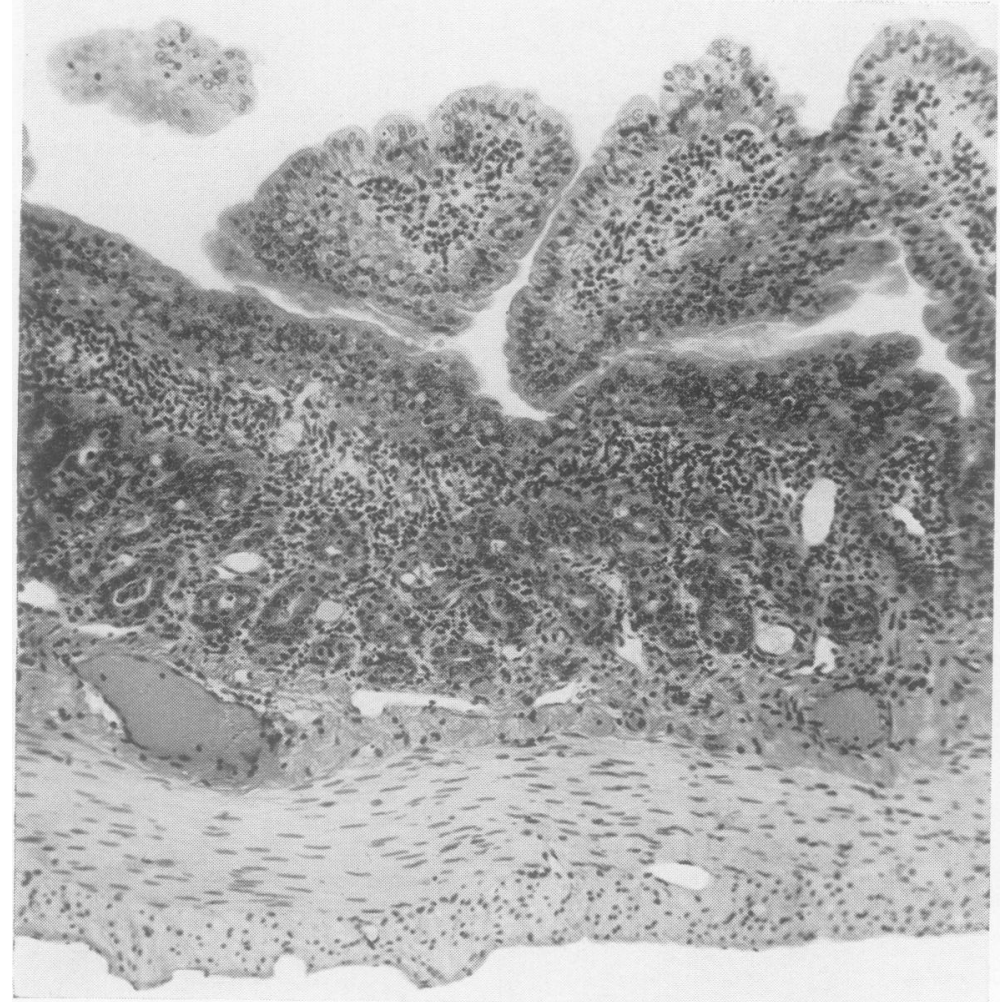

FIG. 3. Section of duodenum of rat injected with colchicine for three days $(0 \cdot 1 \mathrm{mg} . / 100 \mathrm{~g}$. body weight $)$. Haematoxylin and eosin, approximately $\times 125$. Note area of villous atrophy next to an apparently normal villus. Lamina propria again contains large numbers of leucocytes and enlarged blood vessels. The intestine of this rat had a very low maltase activity (group 2, day 3, in Table V). 
TABLE II

ABSORPTION OF VARIOUS SUGARS MEASURED in vivo BY CIRCULATING $50 \mathrm{ML}$. OF $0.9 \% \mathrm{NaCl}$ CONTAINING 500 MG. $\%$ OF A SUGAR THROUGH THE SMALL INTESTINE FOR 15 MINUTES $^{1}$

\begin{tabular}{|c|c|c|c|c|}
\hline Sugar Circulated & $\begin{array}{l}\text { Control } \\
\text { (mg.15 min.) }\end{array}$ & $\begin{array}{l}\text { Colchicine Treated } \\
\text { (mg.15 min.) }\end{array}$ & Percentage Change & $\begin{array}{l}\text { Significance of Difference } \\
\text { between the Means }\end{array}$ \\
\hline \multicolumn{5}{|l|}{ Glucose } \\
\hline Day 1 & $64 \cdot 3 \pm 3 \cdot 5(3)$ & $51 \cdot 7 \pm 2.3(3)$ & $-19 \cdot 6$ & $\mathrm{p}<0.02$ \\
\hline Day 2 & $58.5 \pm 5.7(4)$ & $42 \cdot 7 \pm 5 \cdot 2(4)$ & $-27 \cdot 0$ & $\mathrm{p}>0.4$ \\
\hline Day 3 & $54.0 \pm 3.9(5)$ & $22 \cdot 0 \pm 6 \cdot 6(7)$ & $-59 \cdot 3$ & $\mathrm{p}<0.001$ \\
\hline \multicolumn{5}{|l|}{ Galactose } \\
\hline Day 1 & $62 \cdot 7 \pm 5 \cdot 1(4)$ & $54 \cdot 7 \pm 5 \cdot 1(4)$ & $-12 \cdot 8$ & $\mathrm{p}>0 \cdot 2$ \\
\hline Day 2 & $51 \cdot 5 \pm 4.4(4)$ & $39 \cdot 5 \pm 2 \cdot 4(4)$ & $-23 \cdot 3$ & $p>0.05$ \\
\hline Day 3 & $54 \cdot 1 \pm 4.5(8)$ & $33 \cdot 5 \pm 6 \cdot 5(8)$ & $-38 \cdot 1$ & $\mathrm{p}<0.05$ \\
\hline \multicolumn{5}{|l|}{ Fructose } \\
\hline Day 3 & $19 \cdot 1 \pm 0.99(7)$ & $13 \cdot 4 \pm 2 \cdot 0(7)$ & $-29 \cdot 8$ & $\mathrm{p}<0.05$ \\
\hline \multicolumn{5}{|l|}{ Sorbose } \\
\hline Day 3 & $4.4 \pm 0.8$ & $5 \cdot 3 \pm 0 \cdot 8$ & +20.4 & $p>0.5$ \\
\hline
\end{tabular}

TABLE III

MUCOSAL TRANSFERS OF FLUID, GLUCOSE, AND GALACTOSE BY SACS OF EVERTED PROXIMAL JEJUNUM FROM CONTROL AND COLCHICINE-INJECTED RATS (DAY 3$)^{1}$

Controls (9) Colchicine (8) Percentage Change Significance of Difference

\begin{tabular}{lll} 
Controls $(9) \quad$ Colchicine $(8)$ & $\begin{array}{l}\text { Significance of Difference } \\
\text { between Means }\end{array}$ \\
\hline
\end{tabular}

Glucose

Sac weight (g.)

Fluid transfer (g.)

Glucose transfer (mg.)

Galactose

Sac weight (g.)

Fluid transfer (g.)

Galactose transfer (mg.)
$0.81 \pm 0.02$

$1.09 \pm 0.18$

$19.56 \pm 3.03$

$0.82 \pm 0.04$

$0.42 \pm 0.03$

$15.0 \pm 1.4$
$-15 \cdot 5$

$-15 \cdot 3$

p>0.4

p $>0.5$

三

三 bonate saline containing $500 \mathrm{mg}$. $\%$ glucose or galactose. Incubation period 30 minutes at $38^{\circ} \mathrm{C}$. Buffers in equilibrium with $95 \% 0_{2}, 5 \% \mathrm{CO}_{2}$. Results are expressed as the mean \pm S.E. Figures in brackets indicate number of animals.

depression was significant $(\mathrm{p}<0 \cdot 05)$. Sorbose absorption, however, was not significantly affected by the drug ( $p>0.05$ ) on day 3 . In all these experiments the colchicine was injected intraperitoneally, so that the drug after absorption entered the mucosal cells by their blood or nutrient sides. The actions of the drug so administered can be assumed to come under the heading of 'chronic effects' as the first measurement of absorption was approximately 24 hours after injection. In order to test whether colchicine had an 'acute' or immediate effect on intestinal absorption a $1 \mathrm{mM}$ solution of the drug in $0.9 \% \mathrm{NaCl}$ containing $500 \mathrm{mg} \%$ glucose was circulated through the intestine of three unfasted normal rats for 15 minutes. Two other normal rats were used as controls, $i . . e$, glucose solution circulated without colchicine. Glucose absorption in the two control rats was 68 and $69 \mathrm{mg} . / 15$ minutes respectively. In the three rats circulated with colchicine and glucose, absorption was found to be 83 , 74 , and $78 \mathrm{mg} . / 15$ minutes. These results clearly indicate that colchicine present in the lumen of the intestine has no 'acute' depressive effect on glucose absorption.

EFFECTS ON TRANSFER IN VITRO The transfer of fluid, glucose, and galactose by sacs of everted proximal intestine removed from colchicine-treated rats (day 3) and their controls are shown in Table III. The results are surprising in that the depressions of transfer of glucose and fluid were small (15\%) and were not significant $(p>0 \cdot 4)$. Even the weight of the small intestine was not significantly different in the two groups of rats, a result that contrasts with the data obtained for the dry weight of the intestine on day 3 of colchicine treatment.

A second series of rats was injected with an increased concentration of colchicine in order to check that the drug was effective. In this group the colchicine was given in a single dose $(0 \cdot 2 \mathrm{mg} . / 100 \mathrm{~g}$. body weight) and intestinal function was measured in vivo and in vitro some 20 hours later. The results for glucose transfer in vitro have not been tabulated because, although the mucosal transfer of glucose 
in intestines from seven colchicine-treated rats was depressed by $26 \%$, this depression was not statistically significant $(p>0.05)$. Glucose absorption in vivo, however, was reduced by $49 \%$ in the group of five rats that had this single dose of colchicine $(p<0.01)$. Thus in this series of experiments, as in the previous series, absorption in vivo was more effectively depressed by colchicine than that measured in vitro.

ALIMENTARY TRACT MOTILITY The motility of the alimentary tract in fasted controls and day 3 injected colchicine rats was measured by feeding a barium sulphate meal by stomach tube and measuring the passage of the barium along the alimentary canal. The results are shown in Table IV. The transit time for the barium meal was slower in the colchicinetreated rats.

EFFECT ON MALTASE ACTIVITY Colchicine has been shown to cause a decrease in the activity of both alkaline phosphatase (Fredericsson and Wirsén, 1956) and various oxidative enzymes (Luketic, Myren, Sachs, and Hirschowitz, 1964) present in the mucosal cells but no studies have been undertaken on any possible effects on the digestive enzymes present in the small bowel. Table $\mathrm{V}$ shows the results obtained for the effects of colchicine on intestinal maltase activity. When the maltase activity of colchicine-treated rats (group 1, day 3 ) was compared to that of the controls there was an apparent, but not significant, increase on an absolute basis $(p>0.05)$ and a significant increase on a gram wet weight basis $(p<0.02)$. Assays of maltase activity in three rats that were particularly sensitive to colchicine (group 2, day 3) show quite different results. These rats had a bloody discharge at the anus and at laparotomy their intestines appeared extremely haemorrhagic. Histological sections of the duodenum showed marked changes in the intestine (Figure 3). Maltase activity was significantly depressed in these rats whether the comparison was made on an absolute basis or on a gram wet weight basis. It appears that in rats sensitive to colchicine the drug can profoundly affect intestinal maltase activity. It is interesting to note that the results from Table $\mathrm{V}$ again show that colchicine injections had no significant effect on the wet weight of the small bowel (group 1, day 3). This lack of effect was noted previously in the wet weights of sacs taken from measurement of transfer capacity in vitro (Table III) and again contrasts with the results obtained for the dry weight (Table I).

TABLE IV

EFFECTS OF COLCHICINE (DAY 3) ON INTESTINAL LENGTH AND ALIMENTARY MOTILITY ${ }^{1}$ Controls (6)

Colchicine-treated (5) Percentage Chang

Significance of Difference between Means

Intestinal length (cm.)

Distance of head of column from pylorus (cm.)

Percentage intestine traversed by barium column

${ }^{1}$ Rats were fed $4 \mathrm{ml}$. of a $50 \%$ diluted barium sulphate suspension (diluent $0.9 \% \mathrm{NaCl}$ ) and then killed after 30 minutes. The length of the intestine and the distance the barium column had traversed from the pylorus was measured. Results are expressed as the mean \pm S.E. Figures in brackets represent the number of animals.

$\begin{array}{lll}86 \pm 3 & -8.5 & p>0.05 \\ 60 \pm 6 & -27.7 & p<0.01\end{array}$

$69 \pm 5$

$-21 \cdot 6$ $0<0.001$
TABLE V

MALTASE ACTIVITY OF HOMOGENATES OF RAT SMALL INTESTINE (DAY 3) ${ }^{1}$

\begin{tabular}{|c|c|c|c|c|}
\hline $\begin{array}{l}\text { Controls } \\
\text { (9) }\end{array}$ & $\begin{array}{l}\text { Colchicine } \\
\text { Group } 1 \\
(6)\end{array}$ & $\begin{array}{l}\text { Percentage Change } \\
\text { and Significance } \\
\text { of Difference } \\
\text { between Means } \\
\text { (Group } 1 \text { and } \\
\text { Controls) }\end{array}$ & $\begin{array}{l}\text { Colchicine } \\
\text { Group } 2 \\
\text { (3) }\end{array}$ & $\begin{array}{l}\text { Percentage Change } \\
\text { and Significance } \\
\text { of Difference } \\
\text { between Means } \\
\text { (Group } 2 \text { and } \\
\text { Controls) }\end{array}$ \\
\hline $\begin{array}{l}4 \cdot 09 \pm 0 \cdot 11 \\
1904 \pm 84\end{array}$ & $\begin{array}{l}3.99 \pm 0.23 \\
2353 \pm 254\end{array}$ & $23.6 \%, \bar{p}>0.05$ & $\begin{array}{l}3 \cdot 10 \pm 0 \cdot 07 \\
1035 \pm 91\end{array}$ & $\begin{array}{l}-24.2 \%, \mathrm{p}<0.01 \\
-45.6 \%, \mathrm{p}<0.001\end{array}$ \\
\hline $467 \pm 24$ & $586 \pm 37$ & $25.5 \%, \mathrm{p}<0.02$ & $335 \pm 32$ & $-28.3 \%, p<0.02$ \\
\hline
\end{tabular}

Controls

(9) 


\section{DISCUSSION}

Before the experimental results are discussed, it is germane briefly to list possible effects a drug like colchicine may have on intestinal function. First, and probably the most important, as the drug is a powerful inhibitor of mitosis (Eigsti and Dustin, 1955), it will prevent the normal cellular proliferation from the crypts of the intestine. Thus, as the loss of cells from the tips of the villi continues, the mucosal cell population of the intestine will gradually decrease. Secondly, the drug may directly affect enzymes present in the mucosal cells and thus influence cellular functions and metabolism. It is also likely that the drug will have an influence on the motility of the alimentary tract, splanchnic blood flow, appetite and food intake, liver function and hormonal balance. With such an array of possible actions and interactions the task of interpreting experimental data obtained with this drug should be one of isolating its 'direct actions' from the many 'indirect actions' it may have on intestine.

Because glucose and galactose are actively transported while fructose and glucose are metabolized by the mucosal cells of the small intestine it might be argued that the absorption of these sugars would be especially affected by any factor that depresses cellular metabolism and the supply of energy to the active transport processes. Sorbose, on the other hand, being a sugar that is supposedly absorbed by passive diffusion across the gut wall (Wilson, 1962), should be relatively unaffected by interference with the metabolism of the mucosa. The experimental results obtained in vivo indicate that colchicine treatment, while having a profound effect on glucose, galactose, and fructose absorption, did not depress that of sorbose. These results are thus in keeping with the previous arguments if it is assumed that colchicine treatment affects intestinal cellular metabolism in vivo. The recent experiments of Varró, Blahó, Csernay, Jung, and Szarvas (1965), who found that the rate of blood flow and thus of oxygen supply through the small intestine affected the absorption of glucose but not of sorbose, are pertinent to the colchicine experiments. Of course, this does not necessarily mean that colchicine also acts by reducing intestinal blood flow or oxygen consumption. Further experiments are needed to verify such a hypothesis. Another factor that must be borne in mind with results obtained with sorbose is the accurate measurement of its absorption. This sugar is absorbed slowly in the anaesthetized rat and the amount disappearing from the lumen is correspondingly small. Measurement of its disappearance from the lumen is prone to larger errors than the measurement of the more rapidly absorbed sugars like glucose and galactose. Inhibition of sorbose absorption is thus not easy to demonstrate.

Previous studies with colchicine (Clark and Harland, 1963) showed depression of absorption in conscious rats fed xylose by stomach tube. Colchicine, however, is known to affect intestinal motility (Ferguson, 1952) and it may well affect gastric emptying. In the present study the transit of barium along the bowel of colchicine-treated rats was delayed compared with the transit in fasted control animals. This slowed transit may be due to a delayed gastric emptying and decreased intestinal motility. Because of such effects, absorption results obtained with conscious animals must be treated with caution. Furthermore, the handling of a metabolizable sugar by the liver and kidney may depend on the level attained in the plasma. The finding by Luketic and Shapiro (1964) of a delayed xylose peak in the blood after feeding the pentose to colchicine-treated dogs is thus also difficult to interpret. It is interesting to note in this context that although Luketic and Shapiro interpreted their results to indicate a depressed absorption, they could not find any evidence of a sprue-like morphology in the intestines. In the studies on rats presented in this paper absorption in vivo was also depressed by colchicine but generally little effect on histological structure was observed.

Further evidence that colchicine has profound effects on conscious animals other than that of absorption mechanisms per se is the finding that when the drug was injected in a dose of $0.1 \mathrm{mg} . / 100 \mathrm{~g}$. body weight per day some rats refused to eat their food by the second day while others had varying degrees of anorexia. This depression of food intake has also been mentioned by Ferguson (1952). Such a result makes the comparison of appetite-depressed, colchicine-treated rats with controls that are feeding normally extremely unsatisfactory. Reduced food intake or starvation can depress the absorption of a number of nutrients (Marrazzi, 1940; Larralde, 1947; Levin et al., 1965). As no mention is made of food intake in previous papers on colchicinetreated rats, it must be assumed that either this factor was not taken into account or that the intakes of the treated and control groups were not found to be significantly different. In the present study possible differences in food intake between the colchicine and control groups were avoided by the simple expedient of starving both groups. Differences between the two groups can reasonably be assumed to be due to the actions of colchicine per se and not to nutritional or caloric deficiencies. The use of the fasting condition with injections of colchicine leads to a process of selection of the experimental animals as will be discussed after the results in vitro.

The results obtained from the experiments in 
vitro with intestinal sacs taken from colchicinetreated and control rats are somewhat surprising in that, although a large depression of transfer activity was expected, i.e., from the data obtained in vivo, only small depressions were observed which were not significant. A possible reason for the discrepancy between the effectiveness of colchicine in vivo and in vitro may be the sensitivity of the rats to anaesthesia, surgery, and the technique of measuring absorption. Colchicine-treated rats were usually weaker and more lethargic than controls. Many had signs of obvious diarrhoea while a few had a lowered body temperature. Despite careful attempts to maintain the latter in all animals and to reduce surgical and manipulative trauma to the minimum, colchicine-injected rats may have been acutely sensitive to such procedures. These may depress the general circulation which in turn affects splanchnic circulation and thus intestinal function. Curtis, Lubin, and Drucker (1964) have briefly recorded that haemorrhagic shock greatly depressed glucose absorption in vivo but that if the transport capacity was measured in vitro no significant impairment of this function was found. Such results indicate that depression of absorption by a particular condition in vivo is not necessarily a good indication of its effectiveness in vitro. Similar variations between studies in vivo and in vitro have been noted by Levin et al. (1965).

Although no exact quantitative data on the effectiveness of colchicine in rats was kept, it became obvious during the study that the strain of rats used exhibited three reactions to the combined drug and starvation treatment. The rats either died on the second or subsequent day of the treatment, or they died under the anaesthetic on the day of use, or the rats appeared unaffected by all the experimental procedures and survived. Because the rats in the latter group were presumably the ones least sensitive to colchicine, it is obvious that most of the animals used in this study would be mainly from this group. Thus the method of fasting and injecting colchicine over a three-day period automatically selects those rats that are the most insensitive to colchicine. The wide variation in the histology of the surviving rats injected with colchicine (varying from complete villous atrophy to normal mucosa) confirms the wide variation in sensitivity to the drug. Such variation is mirrored in the data on maltase activity. Neither the intestinal wet weight nor the maltase activity of the colchicine-injected rats of group 1 was depressed; in fact the latter tended to be slightly increased. Yet, in the three animals of group 2 that had bloody diarrhoea after colchicine, both the intestinal weight and the maltase activity were severely depressed. It may be then that the relative absence of significant inhibitions of transfer activity in vitro and of maltase activity could be due to the use of a strain of rats relatively resistant to antimitotic action of colchicine but not to its general toxic effects. Because of this, unequivocal conclusions about the effects of colchicine on sugar and fluid transfers in vitro and on maltase activity must remain sub judice.

Such a reserve of comment does not apply, however, to the results obtained in vivo. In the present study colchicine has been found to have a number of actions on the alimentary tract of the rat in vivo. The motility was depressed, the absorption of both actively transported (glucose and galactose) and metabolized sugars (fructose and glucose) was depressed while the dry weight of the intestine decreased. The drug was also found to have a profoundly depressing effect on the food intake of rats. Because colchicine has so many sites of action in the intact rat (mitosis, motility, appetite), any localization of its depressive actions on absorption to interference with specific cellular mechanisms or systems in the mucosal cell is as yet speculative and unwarranted until further studies are undertaken.

\section{REFERENCES}

Althausen, T. L., and Grodsky, G. M. (1961). Effect of wheat proteins on intestinal absorption in rats. Gastroenterology, 40, 665.

Barry, B. A., Matthews, J., and Smyth, D. H. (1961). Transfer of glucose and fluid by different parts of the small intestine of the rat. J. Physiol. (Lond.), 157, 279-288.

Baserga, A., and Morsiani, M. (1958). Non regenerative enteropathy. Rass. giul. Med., 35, 208-215.

Clark, P. A., and Harland W. A. (1963). Experimental malabsorption with jejunal atrophy induced by colchicine. Brit. J. exp. Path., 44, 520-523.

Curtis, J., Lubin, S., and Drucker, W. R. (1964). Metabolic activity of the rat intestine during hemorrhagic shock. Clin. Res., 12, 343.

Dahlqvist, A. (1961). Determination of maltase and isomaltase activities with a glucose-oxidase reagent. Biochem. J., 80, 547-551.

Eigsti, O. J., and Dustin, P. (1955). Colchicine in Agriculture, Medicine, Biology, and Chemistry. The Iowa State Press, Ames, Iowa.

Ferguson, F. C. Jr. (1952). Colchicine. 1. General pharmacology. J. Pharmacol. exp. Ther., 106, 261-270.

Fredericsson, B., and Wirsén, C. (1956). In-vivo effect of colchicine on alkaline phosphatase of rat intestinal epithelium. Exp. Cell Res., 10, 749-751.

Huggett, A. St. G., and Nixon, D. A. (1957). Use of glucose oxidase, peroxidase, and o-dianisidine in determination of blood and urinary glucose. Lancet, 2, 368-370.

Krebs, H. A., and Henseleit, K. (1932). Untersuchungen über die Harnstoff bildung im Tierkörper. Hoppe-Seylers Z. physiol. Chem., 210, 33-66.

Larralde, J. (1947). Influencia del ayuno sobre la absorción intestinal de glucosa. Rev. esp. Fisiol., 3, 31-38.

Levin, R. J., Newey, H., and Smyth, D. H. (1965). The effects of adrenalectomy and fasting on intestinal function in the rat. J. Physiol. (Lond.), 177, 58-73.

Luketic, G. C., and Shapiro, M. (1964). Effect of colchicine on xylose absorption in dogs. Clin. Res., 12, 31.

—, Myren, J., Sachs, G., and Hirschowitz, B. I. (1964). Effects of therapeutic doses of colchicine on oxidative enzymes in the intestine. Nature (Lond.), 202, 608-609.

Marrazzi, R. (1940). The influence of adrenalectomy and of fasting on the intestinal absorption of carbohydrates. Amer. J. Physiol., 131, 36-42. 
Nelson, N. (1944). A photometric adaptation of the Somogyi method for the determination of glucose. J. biol. Chem., 153, 375-380.

Sheff, M. F., and Smyth, D. H. (1955). An apparatus for the study of in vivo intestinal absorption in the rat. J. Physiol. (Lond.), $128,67 \mathrm{p}$.

Somogyi, M. (1945). A new reagent for the determination of sugars. J. biol. Chem., 160, 61-68.

Varró, V., Blahó, G., Csernay, L., Jung, I., and Szarvas, F. (1965). Effect of decreased local circulation on the absorptive capacity of a small-intestine loop in the dog. Amer. J. dig. Dis., 10 , 170-177.
Williams, A. W. (1963). Experimental production of altered jejunal mucosa. J. Path. Bact., 85, 467-472.

Williams, J. N. Jr., and Laster, L. (1963). Investigation of the use of the albino rat for studying gliadin-induced steatorrhea. Metabolism, 12, 467-471.

Wilson, T. H. (1962). Intestinal Absorption. Saunders, Philadelphia and London.

- , and Wiseman, G. (1954). The use of sacs of everted small intestine for the study of the transference of substances from the mucosal to the serosal surface. J. Physiol. (Lond.), 123, 116-125. 